\title{
A DIMENSÃO PÚBUCA DA COLEÇÃO GILBERTO CHATEAUBRIAND
}

\author{
Vanessa Biazioli Siqueira \\ vanesabiazioli@hotmail.com
}

Esta pesquisa destina-se a estudar o processo de institucionalização da Coleção Gilberto Chateaubriand desde seu início, em 1953, até sua transferência, em 1993, para o Museu de Arte Moderna do Rio de Janeiro (MAM-RJ), em regime de comodato. Os dados aqui apresentados são resultados de levantamento inicial em catálogos de exposições que tratam dessa coleção, jornais e revistas.

Gilberto Renato Allard Chateaubriand Bandeira de Mello iniciou sua coleção, com Paisagem de Itapoã, um presente do pintor José Pancetti, em Salvador.

Porém a Coleção começa a tomar corpo em meados da década de 60, quando G. Chateaubriand se dedica a colecionar, elegendo de acordo com critérios pré-estabelecidos. É nessa época, em 1963, que adquire o Vendedor de frutas, de Tarsila do Amaral e, em 1969, numa exposição retrospectiva de Anita Malfatti na Fundação Armando Álvares Penteado - A Japonesa, Índia e o Farol de Monheagen. Antes disso, entre 1956 e 1959, trabalhou na Europa para o Itamarati como diplomata, fato que o impossibilitou de ter um contato mais direto com a arte nacional, apesar do estimulo recebido do pintor Di Cavalcanti, também vivendo naquele momento na Europa, para que começasse a colecionar. Para formar sua coleção de arte, G. Chateaubriand seguiu os conselhos dos marchands Jean Boghici e Giovana Bonino, bem como do colecionador Aloysio de Paula e do pintor Carlos Scliar. ${ }^{1}$

No entanto, o colecionismo de Chateaubriand difere do colecionismo da geração anterior, dos anos seguintes à Segunda Guerra Mundial, o qual marcou no Brasil a fundação de museus e a formação de coleções privadas de arte internacional. É o caso do Museu de Arte de São Paulo (MASP), fundado por Assis Chateaubriand, pai de Gilberto, e do Museu de Arte Moderna de São Paulo (MAM-SP), fundado por Ciccilo Matarazzo.

É interessante notar que outras coleções se iniciam no mesmo período que a de Gilberto Chateaubriand e, segundo o crítico de arte Tadeu Chiarelli, as Bienais Internacionais de São Paulo - com salas especiais homenageando alternadamente os artistas modernos - foram responsáveis pela legitimação do pássado modernista, um processo que abraçaria também as coleções que se forma-

\footnotetext{
${ }^{1}$ MORAIS, Frederico. Coleção Gilberto Chateaubriand no MAM: arte brasileira, do moderno ao contemporâneo. O Globo. Rio de Janeiro, 21 maio 1981.
} 
vam. "Parece que os organizadores dessa nova política para as salas especiais queriam fazer crer que o modernismo brasileiro, derivado da Semana de 22, sustentava ou era a base para a produção contemporânea surgida após a criação dos museus de arte e sobre tudo, da própria Bienal."2

Nos anos 1970, a Coleção Gilberto Chateaubriand, guardada nos espaços privados de seu proprietário - na fazenda Rio Corrente em Porto Ferreira e em seu apartamento no Rio de Janeiro - passa a ser vista pelo público, por circular amplamente em exposições nacionais e internacionais. A primeira exposição da Coleção, denominada "50 anos de arte brasileira", realiza-se em 1972, na Galeria do Instituto Brasil Estados Unidos (IBEU), no Rio de Janeiro, com curadoria do próprio colecionador, para as comemorações do cinqüentenário da Semana de Arte Moderna de 1922.

Ainda nesse período, em1976, Roberto Pontual lança o primeiro livro sobre a Coleção: Arte brasileira contemporânea. Coleção Gilberto Chateaubriand. Essa publicação tratará basicamente de arte brasileira dos anos 1970, na Coleção Gilberto Chateaubriand.

Em 1978, um incêndio no prédio do MAM-RJ destrói 90\% do acervo e, logo após o incidente, G. Chateaubriand começa a fazer parte de uma comissão de negociações e reconstrução do Museu, para dialogar com artistas e intelectuais manifestantes que reivindicavam "Por um MAM para a cidade do Rio de Janeiro". Três eram os tópicos do manifesto: a reforma jurídica dos estatutos e da área cultural do museu, a participação institucional dos artistas e intelectuais e a profissionalização de todos os setores do MAM-RJ. ${ }^{3}$

O Museu reabre em 1980 e, em 1981, apresenta uma grandiosa mostra da Coleção Gilberto Chateaubriand denominada "Do Moderno ao Contemporâneo", organizada pelo professor de estética da PUC-RJ e artista plástico Fernando Cocchiarale, bem como pelo crítico de arte do Jornal do Brasil Wilson Coutinho. Essa exposição com 411 obras - a maior realizada com a Coleção - traz prestígio para o MAM-RJ, que estava sem nenhum crédito depois do incêndio e lança a Coleção Gilberto Chateaubriand como sendo a melhor representante da arte brasileira.

A exposição é marcada pelo didatismo intencional citada pelo próprio curador:

\footnotetext{
"Mas toda a exposição foi organizada no sentido de colher historicamente, através de décadas, a produção da arte brasileira. Abrindo cada uma, foram escolhidos trechos de textos significativos para exprimir a atmosfera de cada período como o edital da revista Klaxon, de 22; o Manifesto da Poesia Pau-Brasil, de 24; O Antropófago, de 28; um breve comentário, retirado de uma carta escrita por Portinari, em 29, quando estava em Paris como

${ }^{2}$ Tadeu Chiarelli. “Arte em São Paulo e o núcleo modernista da Coleção”. IN: MILLIET, Maria Alice (coord. ed.). Coleção Nemirovsky. Rio de Janeiro: MAM, 2003.

${ }^{3}$ COUTINHO, Wilson. O MAM em alta ansiedade. Jornal do Brasil. Rio de Janeiro, 08 julho 1980.
} 
bolsista (...); e uma parte do famoso e crítico discurso pronunciado no Itamarati, em 1942, por Mário de Andrade (...). Haverá também o Manifesto Ruptura, da década de 50, escrito pelos concretistas paulistas e o neoconcretismo propondo, em oposição à elaboração estritamente geométrica e matemática (...). Dois bichos de Lygia Clark, modelo exemplar das preocupações dos neoconcretos cariocas, estarão expostos. Para explicitar o clima da década de 60, com presença da Nova Figuração, foram escolhidos trechos do catálogo Nova Objetividade, redigido por Hélio Oiticica (...). Para a década de 70, (...) optou-se por expressar esse período, fragmentos de dois textos: Querela do Brasil, de Carlos Zílio, publicado na revista Malazarte, e Cruzeiro do Sul, de Cildo Meireles, quando expôs, em 1970, no MOMA."4

Também houve uma forte "propaganda" do Jornal do Brasil através de Wilson Coutinho, colaborador do jornal e curador da exposição, visando, a valorizar ainda mais a Coleção e dar credibilidade ao MAM-RJ.

No ano seguinte, em 1982, a Coleção Gilberto Chateaubriand faz sua primeira apresentação internacional com a exposição "Brasil: 60 anos de arte moderna”, em Lisboa, na Fundação Calouste Gulbenkian, com curadoria também de Wilson Coutinho. Essa exposição colabora para um momento de internacionalização da arte brasileira.

A crítica de arte Sônia Salzstein chama a atenção para esse fenômeno de "internacionalização que a partir dos anos 80 mudou radicalmente a fisionomia do meio cultural e pôs termo a todo um ciclo histórico de isolamento cultural e de acesso retardatário à informação, fadado a reproduzir desigualdades. Com a internacionalização vimos à arte brasileira finalmente integrar-se ao circuito internacional da arte, e é significativo que tenha sido uma rubrica 'arte brasileira' a ingressar naquele circuito, e não este ou aquele artista, isoladamente." 5

Outra grande exposição da Coleção, "Retrato e Auto-Retrato da Arte Brasileira", realiza-se em 1984 no Museu de Arte Moderna de São Paulo (MAMSP) com mais de 200 obras e curadoria de Frederico Morais, reafirmando a posição da Coleção Gilberto Chateaubriand como representante expressiva de arte brasileira.

Sobre a exposição a crítica Radha Abramo do jornal Folha de São Paulo faz o seguinte comentário:

"São tão ricas as hipóteses do crítico que acompanham a mostra que me obrigam a sugerir que essa exposição (depois de organizada também com preocupação didática) ande para dentro do Brasil a fim de cumprir sua missão de formar cultural e historicamente o povo brasileiro." 6

\footnotetext{
${ }^{4}$ COUTINHO, Wilson. Coleção Gilberto Chateaubriand: Um tratamento de choque para o MAM. Jornal do Brasil, Caderno B. Rio de Janeiro, 16 maio 1981.

${ }^{5}$ Sônia Salzstein. Perspectivas das instituições culturais públicas - um depoimento sobre a situação brasileira. IN: Revista D’Arte. Seminário delineando nortes. São Paulo: Centro Cultural São Paulo. Número especial, novembro 2002.

${ }^{6}$ ABRAMO, Radha. As imagens de nossa arte. Folha de São Paulo. São Paulo, pág. 27, 03 maio 1984.
} 
Em 1986, a função da Coleção acaba legitimando-se, com o segundo livro sobre a Coleção de Roberto Pontual "Entre dois Séculos: arte brasileira do século XX na Coleção Gilberto Chateaubriand", agora não só abordando arte contemporânea, mas também arte dos anos de 1910 a 1986.

Para termos uma noção de como a publicação repercutiu na época, Reynaldo Roels Jr. faz um ensaio em Galeria Revista de Arte, com o seguinte comentário: "O principal é que, até o momento, este é o volume mais abrangente já escrito sobre a pintura e a escultura brasileira a partir do modernismo da Semana de 22."7

Isso só comprova como o segundo livro de Roberto Pontual e a crítica de arte estavam posicionando a Coleção Gilberto Chateaubriand no cenário artístico nacional.

Desde 1981, estavam sendo feitas negociações do Colecionador com a direção do MAM-RJ para que a Coleção passasse em regime de comodato para a instituição, tornando o acesso ao público ainda maior.

A preocupação que o colecionador tem com o destino de sua Coleção é muito bem abordada pela crítica e historiadora de arte, Aracy Amaral. Sua fala vai ao encontro das atitudes e exigências do colecionador G. Chateaubriand com sua coleção de arte em relação ao MAM-RJ:

"Na verdade, para todo colecionador apaixonado, que iniciou há décadas suas aquisições, o futuro de suas coleções é sempre um motivo de preocupação, enigma a ser solucionado enquanto destinação. Talvez a resposta para essas preocupações de nossos colecionadores seria unir seus acervos às coleções já existentes em seus museus, passando a proteger, com auxílio permanente, essas instituições. Ou pressionado-as, com essas doações, a uma programação mínima necessária para a manutenção de um status desejável.”»

O jornal O Estado de São Paulo lança uma nota com o título "Museu a Chateaubriand" declarando que, em meados 1987 o MAM-RJ, passaria a abrigar a maior parte das três mil peças da Coleção Gilberto Chateaubriand e que, paralelamente, seria lançado um livro sobre a Coleção. ${ }^{9}$

Confirmando essa notícia, Reynaldo Roels Jr. diz que o livro “irá servir de guia após a transferência da coleção de Gilberto para o Museu de Arte Moderna do Rio de Janeiro."10

O livro realmente é lançado e tudo indica que acompanhará a Coleção para o MAM-RJ, mas isso não acontece, por causa das exigências do Colecionador, que incluem entre outras coisas uma reserva técnica, equipe de restauro e cuidados para que não haja novo incêndio.

\footnotetext{
${ }^{7}$ ROELS Jr, Reynaldo. Bibliografia Básica. Galeria Revista de Arte. Rio de Janeiro, nº 07, pág. 72, 1987.

8 Aracy Amaral. Apresentação. IN: (org.). Arte Construtiva no Brasil: Coleção Adolpho Leirner. São

Paulo: Companhia Melhoramentos, 1998.

${ }^{9}$ MUSEU a Chateaubriand. O Estado de São Paulo. São Paulo, 18 dez 1986.

${ }^{10}$ ROELS Jr, Reynaldo. Op cite.
} 
Várias são as exigências, até que o colecionador Gilberto Chateaubriand e a direção do Museu entrem em acordo. Feito isto, o contrato é firmado e grande parte da Coleção é levada ao MAM-RJ em 1993.

\section{Referências Bibliográficas}

AMARAL, Aracy (org.). Arte construtiva no Brasil: Coleção Adolpho Leirner. São Paulo: Companhia Melhoramentos, 1998.

Anos 80: o palco da diversidade. Coleção Gilberto Chateaubriand/MAM-RJ. São Paulo: Galeria de arte do SESI, 1995. Catálogo de Exposição.

BATISTA, Marta R.; LIMA, Yone Soares de. Coleção Mário de Andrade. São Paulo: IEB/USP, 1984.

MARINO, João. Coleção de arte brasileira. São Paulo: Raízes Artes Gráficas, 1983.

Do Modernismo ao Contemporaneo. Coleção Gilberto Chateaubriand. Rio de Janeiro:

Museu de Arte Moderna do Rio de Janeiro (MAM-RJ), 1981. Catálogo de Exposição.

Modernidade: Art bresilien du XX siecle. Musée d'Art Moderne de la Ville de Paris. São Paulo: MAM-SP, 1987-88. Catálogo de Exposição.

MORAIS, Fernando. Chatô: o rei do Brasil, a vida de Assis Chateaubriand. São Paulo: Companhia das Letras, 1994.

O Desenho Moderno no Brasil. Coleção Gilberto Chateaubriand/ MAM - RJ. São Paulo: Galeria de Arte do SESI, 1993. Catálogo de Exposição.

Panorama del Arte del Brasil en el siglo XX. Colección Gilberto Chateabriand/ MAM - RJ Buenos Aires: Museu Nacional de Bellas Arte, 1999. Catálogo de Exposição.

PONTUAL, Roberto. Arte brasileira contemporânea. Coleção Gilberto Chateaubriand. Rio de Janeiro: Jornal do Brasil, 1976.

Janeiro: Jornal do Brasil, 1987.

Entre dois séculos: arte brasileira do século XX na coleção Gilberto Chateubriand. Rio de

Portraits of a Country. Brazilian Modern Art from Gilberto Chateubriand. Collection. London: Barbican Art Gallery, 1984. Catálogo de Exposição.

Retrato e auto-retrato da arte brasileira. Coleção Gilberto Chateubriand. São Paulo: MAM-SP, 1984. Catálogo de Exposição.

RIBEIRO, Maria Izabel M. R. B. O musen doméstico: São Paulo, 1890-1920. São Paulo, 1992.Dissertação (Mestrado). ECA/USP.

SALZSTEIN, Sônia; ROELS Jr, Reynaldo (org.). O moderno e o Contemporâneo na Arte

Brasileira. Coleção Gilberto Chateubriand/ MAM - RJ. São Paulo: Museu de Arte de São Paulo Assis Chateubriand, 1998. Catálogo de Exposição.

The Finest Collections from Sister Cities' Museum - Broadening the Horizons. Korea: Pusan Metropolitan Art Museum, 1998. Catálogo de Exposição.

VOGT, M. C.; GERNER, Cordelia (org.). Um olhar brasileiro. Berlim: Deutsch

Brasilianische Kulturelle Vereinigung, 1998. Catálogo de Exposição.

\section{Jornais e Periódicos}

ABRAMO, Radha. As imagens de nossa arte. Folha de São Paulo. São Paulo, pág.27, 03 maio 1984.

. Cores no garimpo. Revista Isto é. São Paulo, n 1.278, pág.96, 30 março 1994.

A novela do MAM. O Globo. Rio de Janeiro, 20 julho 1980.

AQUINO, Flávio de. A maior coleção de arte moderna brasileira. Revista Manchete. Rio de Janeiro, pág. 132 a $138,1981$.

ARESTIZABAL, Irmã. O delírio de colecionar. Revista Arte Hoje, Rio de Janeiro $n^{\circ} 01$, pág. 06 a 15, julho 1997.

BOMBIG, José Alberto. Mecenas escondem obras raras no interior de SP. Folha de São Paulo, Ilustrada. São Paulo, pág.01, 06 fevereiro 1999.

CARVALHO, Mario César. Brasil está entre 200 maiores acervos. Folha de São Paulo,

Caderno 4, pág.01, 24 março 1992. 
COUTINHO, Wilson. O MAM em alta ansiedade. Jornal do Brasil. Rio de Janeiro, 08 abril 1980. . Coleção Gilberto Chateaubriand: Um tratamento de choque para o MAM. Jornal do

Brasil, Caderno B. Rio de Janeiro, 16 maio 1981.

Do moderno ao contemporâneo: A arte brasileira em polêmica. Jornal do Brasil, Caderno B. Rio de Janeiro, 22 maio 1981.

Do moderno ao contemporâneo. Coleção Gilberto Chateaubriand: Roteiro da exposição. Jornal do Brasil. Rio de Janeiro, 15 junho 1981.

- Gilberto Chateaubriand: O fazendeiro de obras-primas.Galeria Revista de Arte. Rio de Janeiro, nº 01 , pág. 06 a 08, 1986.

CRIADO o conselho honorífico do MAC. Diário Popular. São Paulo, 02 setembro 1983.

DIAS, Claudia. A nova arte por Gilberto Chateaubriand. Vidas em Revistas. São Paulo, pág 60 a 61 , fevereiro 2004.

DURÁN, Cristina R. À procura de benfeitores para a memória nacional. Jornal da Tarde, Caderno de Domingo. São Paulo, pág. 10, 18 abril 1999.

GOLIN, Cida. Cores, memória e cenas, a alma brasileira de um colecionador. Revista MARGS. RIO Grande do Sul, n 62 , outubro 2000 .

LOBACHEFF, Geórgia. Colecionar arte pode ser acessível. Jornal da Tarde, Caderno SP. São Paulo, 14 junho 1994.

MEDEIROS, Jotabê. Coleção Chateaubriand chega Finalmente ao Masp. O Estado de São Paulo, Caderno 2. São Paulo, pág. D12, 05 outubro 1998.

MORAIS, Frederico. Coleção Gilberto Chateaubriand no MAM: Arte brasileira do moderno ao contemporâneo. O Globo. Rio de Janeiro, 21 maio 1981.

MUSEU a Chateaubriand. O Estado de São Paulo. São Paulo, 18 dezembro 1986.

PASSOS, Joice Gumiel. Do moderno ao contemporâneo. Diário do Paraná. Paraná, 29 julho 1981.

PIZA, Daniel. Exposição conta história do desenho brasileiro. Folha de São Paulo, Caderno 4, São Paulo, pág. 08, 28 junho 1993.

ROELS Jr, Reynaldo. Bibliografia básica. Galeria Revista de Arte. Rio de Janeiro, nº 07 pág. $72,1987$.

RYFF, Luiz Antônio. Telas Falsas expõem falhas do mercado. Folha de São Paulo, Caderno 5. São Paulo, pág. 01, 18 fevereiro 1995.

SEMINÁRIO delineando nortes. Revista D’Arte São Paulo: Centro Cultural São Paulo. Número especial, novembro 2002.

SILVA, Beatriz Coelho. MAM e as novas obras de Gilberto Chateaubriand. O Estado de São Paulo, Caderno 2. São Paulo, pág. D3, 02 fevereiro 2004.

VALIOSA como um museu. Revista Veja. São Paulo, pág. 108 a 111, 02 maio 1984.

Vanessa Biazioli Siqueira. Mestranda pelo Departamento de Artes Plásticas da Escola de Comunicações e Artes (ECA) da Universidade de São Paulo (USP), sob orientação do Prof. Dr. Tadeu Chiarelli. Bacharel em História pela Faculdade de Direito, História e Serviço Social da Universidade Estadual Paulista (Unesp) Campus de Franca, 1997, é membro do Centro de Pesquisa de Arte e Fotografia (CPArte\&Foto) também sob orientação do Prof. Dr. Tadeu Chiarelli e foi educadora de arte em várias exposições (Paço das Artes (2003), China - Os Guerreiros de Xi'an e os Tesouros da Cidade Proibida (2003), Albert Eckout- Retorno ao Brasil (2003), 25a. Bienal Internacional de São Paulo (2002), entre outras). 